\title{
Small intestinal ulceration secondary to carcinoid tumour arising in a Meckel's diverticulum
}

\author{
W G McCluggage, L McConnell, J M Sloan, P K Ellis, S T Irwin
}

Department of Pathology, Royal Group of Hospitals Trust, Grosvenor Road, Belfast BT12 6BL, UK W G McCluggage J M Sloan

Department of Colorectal Surgery, Royal Group of Hospitals Trust

L McConnell $\mathrm{S}$ T Irwin

Department of Radiology, Royal Group of Hospitals Trust

P K Ellis

Correspondence to: Dr W G McCluggage.

Accepted for publication 25 August 1998

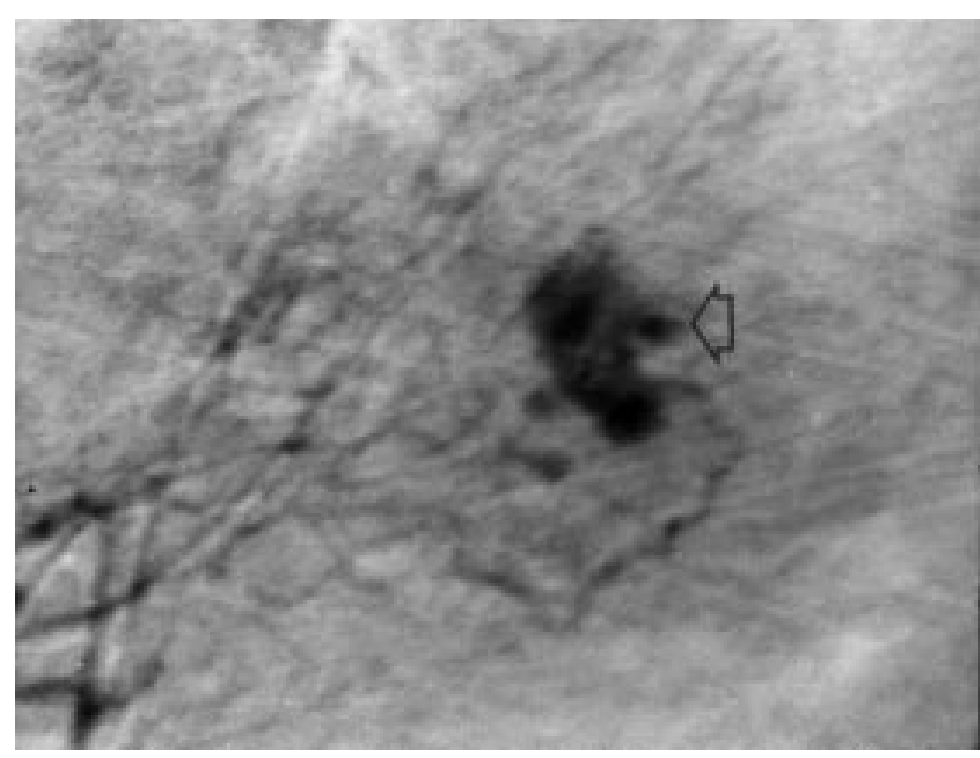

Figure 1 Superior mesenteric arteriogram with superselection of ileal branch. Notice the

active extravasation of contrast material representing the bleeding point (arrow).

\begin{abstract}
A solitary small intestinal ulcer associated with a carcinoid tumour in a nearby Meckel's diverticulum was found in a 77 year old man presenting with massive rectal bleeding. Angiography and a radioisotope study localised the bleeding to the ileum. At operation, the Meckel's diverticulum was identified, with bleeding from an ulcer just distal to it. Pathological examination revealed a small carcinoid tumour confined to the Meckel's diverticulum. Close to the opening of the diverticulum, within the ileum, a well demarcated ulcer was present. Histology showed a non-specific ulcer which eroded a large blood vessel. This is the first documented occurrence of solitary small intestinal ulceration in association with a carcinoid tumour. Carcinoid tumour should be added to the list of possible causes of small intestinal ulceration. The ulceration may be secondary to release of cytokines by the tumour.

(f Clin Pathol 1999;52:72-74)
\end{abstract}

Keywords: carcinoid tumour; small intestine; ulcer; Meckel's diverticulum

Carcinoid tumour is the most common neoplasm to arise within the small intestine. Small intestinal infarction secondary to elastic vascular sclerosis of mesenteric blood vessels is now well described in association with carcinoid tumour. ${ }^{1-5}$ In this report we describe a hitherto unreported phenomenon in which a solitary well demarcated small intestinal ulcer was associated with a carcinoid tumour in a nearby Meckel's diverticulum. We speculate on the possible pathogenesis of the small intestinal ulceration.

\section{Case report}

A 77 year old man presented with a three day history of abdominal pain, lethargy, and weakness. His only drugs were omeprazole $(20 \mathrm{mg}$ daily) for oesophagitis and thyroxine for hypothyroidism. While in hospital he passed a large
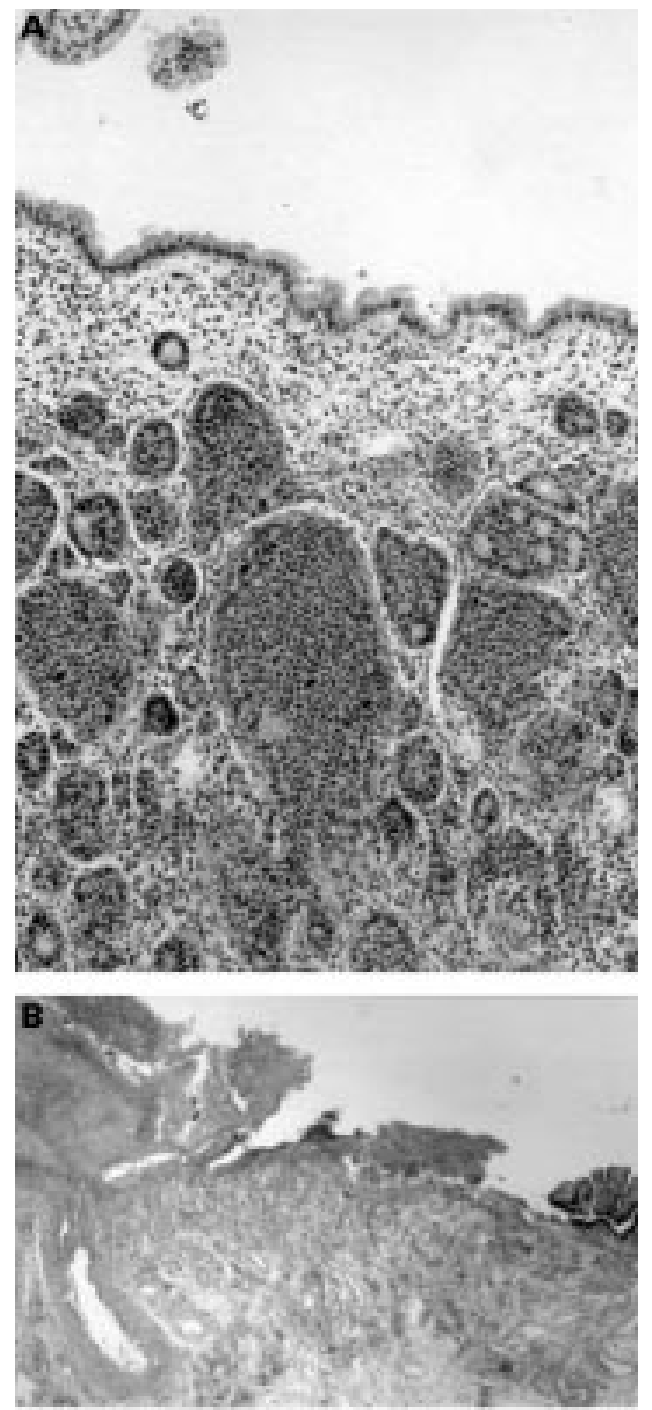

Figure 2 (A) Carcinoid tumour involving mucosa and submucosa of Meckel's diverticulum. (B) Well demarcated ulcer within small intestine. There is erosion of a large submucosal blood vessel. 
amount of fresh blood from the rectum. A selective mesenteric arteriogram showed an active bleeding point from a branch of the superior mesenteric artery within the distal ileum (fig 1). A technetium labelled colloid isotope scan confirmed active bleeding, localised to the distal ileum. At laparotomy, a Meckel's diverticulum was identified, $80 \mathrm{~cm}$ from the ileocaecal valve. This was resected along with a length of ileum. Primary anastomosis was performed and the postoperative period was uneventful.

\section{Pathological findings}

The surgical specimen comprised a $9 \mathrm{~cm}$ length of small intestine with a Meckel's diverticulum situated on the anti-mesenteric border. A $2 \mathrm{~cm}$ well demarcated area of mucosal ulceration was present $2 \mathrm{~cm}$ distal to the opening of the Meckel's diverticulum. A $1 \mathrm{~cm}$ nodule was present within the wall of the Meckel's diverticulum.

Histological examination of the nodule within the diverticulum showed a typical carcinoid tumour within the mucosa and submucosa (fig 2A). The tumour had insular and trabecular growth patterns and consisted of cells showing little nuclear pleomorphism. Mitotic figures were not identified. There was no evidence of vascular invasion. The tumour showed diffuse positive immunohistochemical staining with the neuroendocrine marker chromogranin A. Gastric mucosa was not identified within the diverticulum.

Histological examination of the ulcer showed surface fibrinous debris with underlying inflammatory granulation tissue (fig 2B). There was erosion of a large submucosal blood vessel. There was no evidence of tumour infiltration, vasculitis, or amyloid deposition, and there were no features to suggest Crohn's disease or coeliac disease.

\section{Discussion}

Solitary small intestinal ulcers are relatively rare. Possible causes include tumours, ischaemia, vasculitis, amyloidosis, coeliac disease, Crohn's disease, radiation, endometriosis, and specific infections. ${ }^{6}$ Small intestinal neoplasms which may present as solitary ulcers include adenocarcinoma, malignant lymphoma, and stromal tumours. Ulceration can also occasionally occur in the small intestine proximal to an obstructing lesion. The conditions mentioned above were excluded by a combination of clinical and pathological features. In the 1960s there was an increase in the incidence of non-specific small intestinal ulcers caused by ingestion of enteric coated potassium preparations. ${ }^{78}$ Similar changes can be secondary to non-steroidal anti-inflammatory drugs. ${ }^{9}$ In the present case, the patient was not receiving any of these agents. When other possible causes of small intestinal ulceration are excluded, there remains a group of patients where no apparent cause is found. Such cases have been labelled as "primary non-specific" ulcer.
Anthony and Drury ${ }^{1}$ in 1970 were the first to describe an association between small intestinal carcinoid tumour and elastic vascular sclerosis of the mesenteric blood vessels. In this condition there is an accumulation of elastic fibres in the intima of mesenteric blood vessels which may result in ischaemic necrosis and infarction of the small intestine. ${ }^{1-5}$ Such vascular changes were not identified in the present case despite the examination of multiple histological sections. A recent report has described an ileal carcinoid which was associated with diffuse vascular proliferation within the lamina propria both proximal and distal to the tumour. ${ }^{10}$ This resulted in gastrointestinal bleeding. The authors demonstrated the presence of transforming growth factor $\alpha$, a known angiogenic factor, within tumour cells and it was speculated that this was the cause of the vascular proliferation.

We are not aware of any previous reports of a solitary well demarcated small intestinal ulcer associated with a carcinoid tumour. Given their close proximity, we feel it is likely that the ulcer was secondary to the carcinoid. Previous studies have shown a variety of cytokines within carcinoids $^{11}{ }^{12}$ and it is possible that the ulcer in the present case was caused by production of cytokines by the tumour. Cytokines which have been found within carcinoid tumours include transforming growth factor $\alpha$, transforming growth factor $\beta$, platelet derived growth factor, insulin-like growth factor-I, and acidic fibroblast growth factor. ${ }^{11}{ }^{12}$ These cytokines have been demonstrated by a variety of methods, including immunohistochemistry and in situ hybridisation.

The carcinoid in the present case involved a Meckel's diverticulum. Various neoplasms may arise in a Meckel's diverticulum and carcinoid tumour is the commonest of these. ${ }^{13}$ Gastric mucosa may be present in a Meckel's diverticulum and can give rise to peptic ulceration, either within the diverticulum or in the adjacent ileum. However, gastric mucosa was not identified in the present case despite careful examination of the specimen.

In conclusion, we describe a solitary small intestinal ulcer associated with a carcinoid tumour arising in a nearby Meckel's diverticulum. This association has not previously been reported. The ulcer may be secondary to release of cytokines by tumour cells and may be a direct effect of elaboration of these into the intestinal lumen. Carcinoid tumour should be added to the list of possible causes of small intestinal ulceration. Further cases should be documented to ascertain if a significant association exists.

1 Anthony PP, Drury RBA. Elastic vascular sclerosis of mesenteric blood vessels in argentaffin carcinoma. 7 Clin Pathol 1970;23:110-18.

2 Qizilbash AH. Carcinoid tumors, vascular elastosis and ischaemic disease of the small intestine. Dis Colon Rectum 1977;20:554-60.

3 Harvey JN, Deuyer ME, Da Costa P. Intestinal infarction caused by carcinoid associated elastic vascular sclerosis: early presentation of a small ileal carcinoid tumour. Gut early presentation

4 Bessell JR, Karatassas A, Allen PW. Intestinal ischaemia associated with carcinoid tumour: a case report with review of the pathogenesis. $\mathcal{F}$ Gastroenterol Hepatol 1994;9:304-7. 
5 Strobbe L, D'Hondt ED, Ramboer C, et al. Ileal carcinoid tumors and intestinal ischemia. Hepatogastroenterology 1994:41:499-502.

6 Whitehead R. Gastrointestinal and oesophageal pathology, 2nd ed. Edinburgh: Churchill Livingstone, 1995:665-85.

7 Wilson IH, Cooley NV, Luibel FJ. Nonspecific stenosing small bowel ulcers. Am f Gastroenterol 1968;50:449-55.

8 Baker DR, Schrader WH, Hitchcock CR. Small bowel ulceration apparently associated with thiazide and potassium therapy. FAMA 1964;90:586-90.

9 Madhok R, MacKenzie JA, Lee FD, et al. Small bowel ulceration in patients receiving non-steroidal antiinflammatory drugs for rheumatoid arthritis. $Q$ Med $\mathscr{f}$ 1986;225:53-8.
10 Cai YC, Barnard G, Hiestand L, et al. Florid angiogenesis in mucosa surrounding an ileal carcinoid tumor expressing transform $1373-7$.

11 Krishnamurthy S, Dayal Y. Immunohistochemical expression of transforming growth factor alpha and epidermal growth factor receptor in gastrointestinal carcinoids. Am $\mathcal{F}$ Surg Pathol 1997;21:327-33.

12 LaRosa S, Chiaravalli AM, Capella C, et al. Immunohistochemical localization of acidic fibroblast growth factor in normal human enterochromaffin cells and related gastrointestinal tumours. Virchows Arch 1997;430:117-24.

13 Weinstein EC, Dockerty MB, Waugh LJM. Neoplasms of Meckel's diverticulum. Int Abst Surg 1963;116:103-11.

\section{Fournal of Clinical Pathology - http://www.jclinpath.com}

Visitors to the world wide web can now access the fournal of Clinical Pathology either through the BMJ Publishing Group's home page (http://www.bmjpg.com) or directly by using its individual URL (http://www.jclinpath.com). There they will find the following:

- Current contents list for the journal

- Contents lists of previous issues

- Members of the editorial board

- Information for subscribers

- Instructions for authors

- Details of reprint services.

A hotlink gives access to:

- BMJ Publishing Group home page

- British Medical Association web site

- Online books catalogue

- BMJ Publishing Group books.

The web site is at a preliminary stage and there are plans to develop it into a more sophisticated site. Suggestions from visitors about features they would like to see are welcomed. They can be left via the opening page of the BMJ Publishing Group site or, alternatively, via the journal page, through "about this site". 